\title{
Phosphatidylinositol metabolism in rat hepatocytes stimulated by vasopressin
}

\author{
Christopher J. KIRK and Robert H. MICHELL \\ Department of Biochemistry, University of Birmingham, P.O. Box 363, Birmingham B15 2TT, U.K. \\ and Douglas A. HEMS* \\ Department of Biochemistry, St. George's Hospital Medical School, London SW17 ORE, U.K.
}

(Received 21 July 1980/Accepted 4 September 1980)

\begin{abstract}
In isolated rat hepatocytes, vasopressin evoked a large increase in the incorporation of $\left.{ }^{[2} \mathrm{P}\right] \mathrm{P}_{1}$ into phosphatidylinositol, accompanied by smaller increases in the incorporation of $\left[1-{ }^{14} \mathrm{C}\right]$ oleate and $\left[\mathrm{U}-{ }^{14} \mathrm{C}\right]$ glycerol. Incorporation of these precursors into the other major phospholipids was unchanged during vasopressin treatment. Vasopressin also promoted phosphatidylinositol breakdown in hepatocytes. Half-maximum effects on phosphatidylinositol breakdown and on phosphatidylinositol labelling occurred at about $5 \mathrm{~nm}$-vasopressin, a concentration at which approximately half of the hepatic vasopressin receptors are occupied but which is much greater than is needed to produce half-maximal activation of glycogen phosphorylase. Insulin did not change the incorporation of $\left[{ }^{32} \mathrm{P}\right] \mathrm{P}_{\mathrm{i}}$ into the phospholipids of hepatocytes and it had no effect on the response to vasopressin. Although the incorporation of $\left[{ }^{32} \mathrm{P}\right] \mathrm{P}_{1}$ into hepatocyte lipids was decreased when cells were incubated in a $\mathrm{Ca}^{2+}$-free medium, vasopressin still provoked a substantial stimulation of phosphatidylinositol labelling under these conditions. Studies with the antagonist [1- $(\beta$-mercapto- $\beta, \beta$-cyclopentamethylenepropionic acid),8-arginine]vasopressin indicated that the hepatic vasopressin receptors that control phosphatidylinositol metabolism are similar to those that mediate the vasopressor response in vivo. When prelabelled hepatocytes were stimulated for $5 \mathrm{~min}$ and then subjected to subcellular fractionation, the decrease in $\left[{ }^{3} \mathrm{H}\right]$ phosphatidylinositol content in each cell fraction was approximately in proportion to its original phosphatidylinositol content. This may be a consequence of phosphatidylinositol breakdown at a single site, followed by rapid phosphatidylinositol exchange between membranes leading to re-establishment of an equilibrium distribution.
\end{abstract}

Recent work has established that vasopressin can exert control over several facets of hepatic metabolism; it stimulates gluconeogenesis and glycogenolysis, and it inhibits the synthesis of glycogen, fatty acids and ketone bodies (Hems \& Whitton, 1973; Ma \& Hems, 1975; Williamson et al., 1980). At present, vasopressin is the most potent known hormonal activator of glycogen phosphorylase (Hems et al., 1978a). Cyclic nucleotides do not appear to be implicated in these hepatic actions of vasopressin (Kirk \& Hems, 1974; Hems et al., $1978 b$ ) and recent studies have indicated that a rise in cytosolic $\mathrm{Ca}^{2+}$ concentration may be the essential intracellular mediator of these responses. In particular, hepatic responses to vasopressin require the

* Deceased. presence of extracellular $\mathrm{Ca}^{2+}$ (Stubbs et al., 1976; Whitton et al., 1977; Keppens et al., 1977; Garrison et al., 1979) and they are accompanied by $\mathrm{Ca}^{2+}$ fluxes into and out of the stimulated cells (Keppens et al., 1977; Blackmore et al., 1978; Chen et al., 1978). Two other hormones that seem to control the metabolism of rat liver through mechanisms similar to, though possibly not identical with, that of vasopressin are adrenaline acting at $\alpha$-receptors and angiotensin (Keppens et al., 1977; AssimacopoulosJeannet et al., 1977; Garrison et al., 1979).

Associated with the effects of vasopressin, angiotensin II and $\alpha$-adrenergic stimuli on the central metabolic pathways of the liver there is a marked stimulation of the metabolism of phosphatidylinositol (Kirk et al., 1977, 1978, 1979, 1980; Billah \& Michell, 1978, 1979; Tolbert et al., 1980). Similar 
responses, consisting of enhanced phosphatidylinositol breakdown followed by its resynthesis, occur in a variety of cells treated with $\mathrm{Ca}^{2+}$-mobilizing hormones (Michell, 1979). It has been suggested that such responses are involved in the mechanism(s) whereby these hormones provoke intracellular $\mathrm{Ca}^{2+}$ mobilization (Michell, 1975, 1979).

In the present paper, we describe some detailed studies of the effects of vasopressin on the metabolism of phosphatidylinositol in rat hepatocytes.

\section{Materials and methods}

\section{Preparation and incubation of hepatocytes}

For the experiments described in Fig. 1 and Table 1 , hepatocytes were isolated from fed male Wistar rats $(200-250 \mathrm{~g})$ by collagenase perfusion as described previously (Kirk et al., 1977). For all other experiments, hepatocytes were prepared by a modification of this method in which: (1) $\mathrm{Ca}^{2+}$ was added to the perfusion medium (final concentration $2.5 \mathrm{mM}$ ) together with collagenase $(0.04 \%, w / v)$ after perfusion for $10 \mathrm{~min}$ in the absence of $\mathrm{Ca}^{2+}$ (Seglen, 1976); and (2) the final resuspension medium in which experiments were performed did not contain bovine serum albumin. Hepatocytes were resuspended to a final concentration of about $12 \mathrm{mg}$ dry $\mathrm{wt} . / \mathrm{ml}$, as determined in duplicate for each cell preparation. Cell viability was judged to be satisfactory by the criteria described previously (Hems et al., 1978a).

Portions of the hepatocyte suspension were incubated in plastic scintillation vials in a shaking water bath at $37^{\circ} \mathrm{C}$. The vials were gassed with $\mathrm{O}_{2} / \mathrm{CO}_{2}(19: 1)$ at the beginning of the incubation period, and every $20 \mathrm{~min}$ thereafter. In the early labelling experiments, the results of which are described in Fig. 1 and Table 1 , incubations were commenced with the addition of $1 \mathrm{ml}$ of a concentrated cell suspension to plastic vials containing radioactive precursors and vasopressin in $1 \mathrm{ml}$ of bicarbonate-buffered saline (Krebs \& Henseleit, 1932). In subsequent labelling experiments, hepatocytes were pre-incubated in bulk with $\left[{ }^{32} \mathrm{P}\right]$ orthophosphate for $20 \mathrm{~min}$ and experimental incubations were commenced with the addition of $1 \mathrm{ml}$ of the pre-incubated suspension to vials already containing hormones in buffer $(10-30 \mu 1)$. Basal phosphatidylinositol labelling in these experiments was determined in samples of hepatocyte suspensions extracted immediately after the pre-incubation period. The influence of vasopressin on total hepatic phosphatidylinositol concentration was determined by measuring phosphatidylinositol lipid phosphorus or by measuring the disappearance of the lipid that had been pre-labelled with $\left[2-{ }^{3} \mathrm{H}\right] m y o$-inositol. In the latter case, hepatocytes were prepared from rats that were injected with $30 \mu \mathrm{Ci}$ of $\left[2-{ }^{3} \mathrm{H}\right] m y o$-inositol $20 \mathrm{~h}$ previously. In all experiments concerning phosphatidylinositol degradation, $1 \mathrm{ml}$ portions of cell suspensions were added to plastic vials containing hormone additions in $10-30 \mu \mathrm{l}$ of buffer.

\section{Lipid extraction and isolation}

In early experiments where there was no preincubation period (Fig. 1, Table 1), incubations were terminated by the addition of 0.1 vol. of trichloroacetic acid $(80 \%, \mathrm{v} / \mathrm{v})$, and lipids were extracted (Kirk et al., 1979) and separated by t.l.c. (Kirk et al., 1977) as described previously. All other incubations were terminated with the addition of $3.75 \mathrm{vol}$. of chloroform/methanol $(1: 2, \mathrm{v} / \mathrm{v})$, the lipids extracted by the method of Lapetina \& Michell (1972) and phosphatidylinositol separated from other lipids by chromatography on formaldehydetreated paper (Kirk et al., 1979).

The radioactivity in ${ }^{32} \mathrm{P}$-labelled phospholipids separated by t.l.c. was determined by liquid-scintillation spectrometry of the silica-gel-bound lipids. Radioactivity in ${ }^{14} \mathrm{C}$ - or ${ }^{3} \mathrm{H}$-labelled phospholipids was determined by liquid-scintillation spectrometry after they were eluted from the silica gel with chloroform/methanol/ $\mathrm{NH}_{3}$ (sp.gr. 0.88) (50:50:1, by vol.). Radioactivity in [ $\left.{ }^{32} \mathrm{P}\right]$ phosphatidylinositol separated by paper chromatography was determined by Cerenkov counting after the wet-ashing of lipid samples in $\mathrm{HClO}_{4}$ (Jones et al., 1979). Initial experiments revealed that greater than $98 \%$ of the radioactivity of phospholipids extracted from hepatocytes labelled with $\left[2-{ }^{3} \mathrm{H}\right]$ myo-inositol in vivo was located in phosphatidylinositol. Consequently, phosphatidylinositol degradation was assessed by measuring the loss of radioactivity from the total cell lipid by liquid-scintillation spectrometry.

\section{Subcellular fractionation}

All manipulations were performed at $0-4^{\circ} \mathrm{C}$. Hepatocyte suspensions were sedimented by centrifugation at $500 \mathrm{~g}$ for $1 \mathrm{~min}$ to yield $2.5-3 \mathrm{ml}$ of packed cells and resuspended in $8 \mathrm{vol}$. $(20-24 \mathrm{ml})$ of homogenization medium containing $0.3 \mathrm{M}$-sucrose and $1 \mathrm{~mm}$-EDTA. The $\mathrm{pH}$ of this medium, which was used for all subsequent manipulations including resuspension of sedimented fractions, was adjusted to 7.0 with $\mathrm{NaHCO}_{3}$. The hepatocytes were homogenized with 60-70 strokes of a tight-fitting Dounce homogenizer (Blaessig Glass, Rochester, NY, U.S.A.), when more than $90 \%$ of the cells were disrupted as observed by phase-contrast microscopy.

A portion of the homogenate was stored at $-20^{\circ} \mathrm{C}$ for analysis and the remainder was centrifuged at $1000 \mathrm{~g}$ for $10 \mathrm{~min}$. The pellet thus sedimented was washed twice by resuspension in $5 \mathrm{ml}$ of medium followed by centrifugation at $1000 \mathrm{~g}$ for $10 \mathrm{~min}$. The final pellets were resuspended to $5 \mathrm{ml}$ 
('nuclear' fraction). The combined supernatants were centrifuged at $5000 \mathrm{~g}$ for $10 \mathrm{~min}$, and the pellets were resuspended and sedimented twice more from $3 \mathrm{ml}$ of medium at $5000 \mathrm{~g}$ for $10 \mathrm{~min}$. The final pellets were resuspended to $5 \mathrm{ml}$ ('mitochondrial' fraction). The combined supernatants were centrifuged at $12000 \mathrm{~g}$ for $20 \mathrm{~min}$. The pellets were washed once by resuspension in $3 \mathrm{ml}$ of medium and sedimented at $12000 \mathrm{~g}$ for $20 \mathrm{~min}$. The final pellets were resuspended in $5 \mathrm{ml}$ ('light-mitochondrial' or 'lysosomal' fraction). The combined supernatants were centrifuged at $144000 \mathrm{~g}$ for $40 \mathrm{~min}$ to yield a 'particle-free supernatant' and a sedimented 'microsomal' pellet. The latter pellet was resuspended to a volume of $5 \mathrm{ml}$. Samples of these fractions were immediately subjected to lipid extraction, and the remainder was used for other analyses either immediately or after storage at $-20^{\circ} \mathrm{C}$.

\section{Enzyme assays}

These were performed in duplicate, usually on fractions that had been stored at $-20^{\circ} \mathrm{C}$ and thawed only once.

Succinate dehydrogenase (EC 1.3.99.1) and alkaline phosphodiesterase I (EC 3.1.4.1) were measured as described by Lloyd-Davies et al. (1972). 5'Nucleotidase (EC 3.1.3.5) was measured essentially by the method of Michell \& Hawthorne (1965), but the $P_{i}$ liberated was determined by the method of Baginski et al. (1967). $\beta$-Glucuronidase (EC 3.2.1.31) and arylesterase (EC 3.1.1.2) were assayed as described by Shephard \& Hübscher (1969).

Adenylate cyclase (EC 4.6.1.1) was assayed in incubations lasting $10 \mathrm{~min}$ at $30^{\circ} \mathrm{C}$ by a modification of the method of Houslay et al. (1976) in which residual ATP was removed from the assay mixture by the addition of $0.045 \mathrm{~g}$ of neutral alumina (dry solid) to each tube followed by vortex-mixing and centrifugation. Glucagon-stimulated adenylate cyclase activity was determined in the presence of $1 \mu \mathrm{M}$-glucagon. Cyclic AMP formed in the adenylate cyclase assays was determined in heat-inactivated assay medium as described previously (Kirk \& Hems, 1974).

\section{Chemical methods}

Protein and DNA were determined as described by Lloyd-Davies et al. (1972). $P_{1}$ was measured as described by Jones \& Michell (1974).

\section{Materials}

Bovine serum albumin (fraction V) was supplied by Miles Laboratories (U.K.). Collagenase, vasopressin (grade VI), phospholipid standards, neutral alumina (WN3) and substrates for the determination of enzyme activities were from Sigma Chemical Co.

$$
\left[{ }^{32} \mathrm{P}\right] \mathrm{P}_{\mathrm{i}}, \quad\left[2-{ }^{3} \mathrm{H}\right] \text { myo-inositol, }\left[\mathrm{U}^{14} \mathrm{C}\right] \text { glycerol, }
$$

$\left[1-{ }^{14} \mathrm{C}\right]$ oleic acid and $\left[8-{ }^{3} \mathrm{H}\right]$ adenosine $3: 5$-cyclic monophosphate were obtained from The Radiochemical Centre.

$[1$ - $(\beta$ - Mercapto - $\beta, \beta$ - cyclopentamethylenepro pionic acid),8-arginine $]$ vasopressin ([1-\{ $\alpha$-(1-mercaptocyclohexyl)acetic acid \},8-arginine]vasopressin) was a generous gift from Professor M. Manning, Medical College of Ohio, Toledo, OH, U.S.A.

\section{Results}

Influence of vasopressin on the incorporation of precursors into hepatocyte phospholipids

The incorporation of $P_{1}$ into major hepatic phospholipids followed a rising time course over $60 \mathrm{~min}$ incubation (Fig. 1) and a constant rate of $\left.{ }^{32} \mathrm{P}\right] \mathrm{P}_{\mathrm{i}}$ labelling was only achieved after about $20 \mathrm{~min}$. Hence, in subsequent labelling experiments, hormone treatment was commenced after $20 \mathrm{~min}$ pre-incubation with $\left[{ }^{32} \mathrm{P}\right] \mathrm{P}_{\mathrm{i}}$. Vasopressin significantly stimulated the incorporation of $\mathrm{P}_{1}$ into phosphatidylinositol at all times (Fig. $1 ; P<0.01$ ). The hormone did not significantly change the labelling of five other hepatic phospholipids. The apparent stimulations of the low rates of $P_{i}$ incorporation into sphingomyelin and lysophosphatidylcholine were not statistically significant and probably resulted from cross contamination with phosphatidylinositol during t.l.c.

Vasopressin also enhanced the incorporation of $\left[\mathrm{U}-{ }^{14} \mathrm{C}\right.$ lglycerol and of albumin-bound $\left[1-{ }^{14} \mathrm{C}\right]$ oleic acid into phosphatidylinositol, but not into phosphatidylcholine or phosphatidylethanolamine (Table 1). The rates at which these two precursors were incorporated into hepatocyte phospholipids in the absence of vasopressin were similar to those observed in previous studies (Ontko, 1972; Groener \& Van Golde, 1977).

\section{Influence of vasopressin on phosphatidylinositol breakdown}

Vasopressin caused a small, but rapid, breakdown of phosphatidylinositol in hepatocytes. The time course of this breakdown, which was similar whether detected as a decrease in the concentration of phosphatidylinositol or as a loss of radioactivity from the phosphatidylinositol of hepatocytes prelabelled with $\left[2-{ }^{3} \mathrm{H} \mid m y o\right.$-inositol in vivo, is shown in Fig. 2. A statistically significant breakdown of hepatic phosphatidylinositol was discernible within 5 min of hormone treatment, and maximal depletion of about $10 \%$ of the lipid occurred 10 min later.

Concentration dependence of vasopressin-stimulated phosphatidylinositol breakdown and resynthesis, and the effects of $\mathrm{Ca}^{2+}$ depletion and insulin

The concentration curve describing vasopressin-stimulated $P_{i}$ incorporation into hepatocyte 

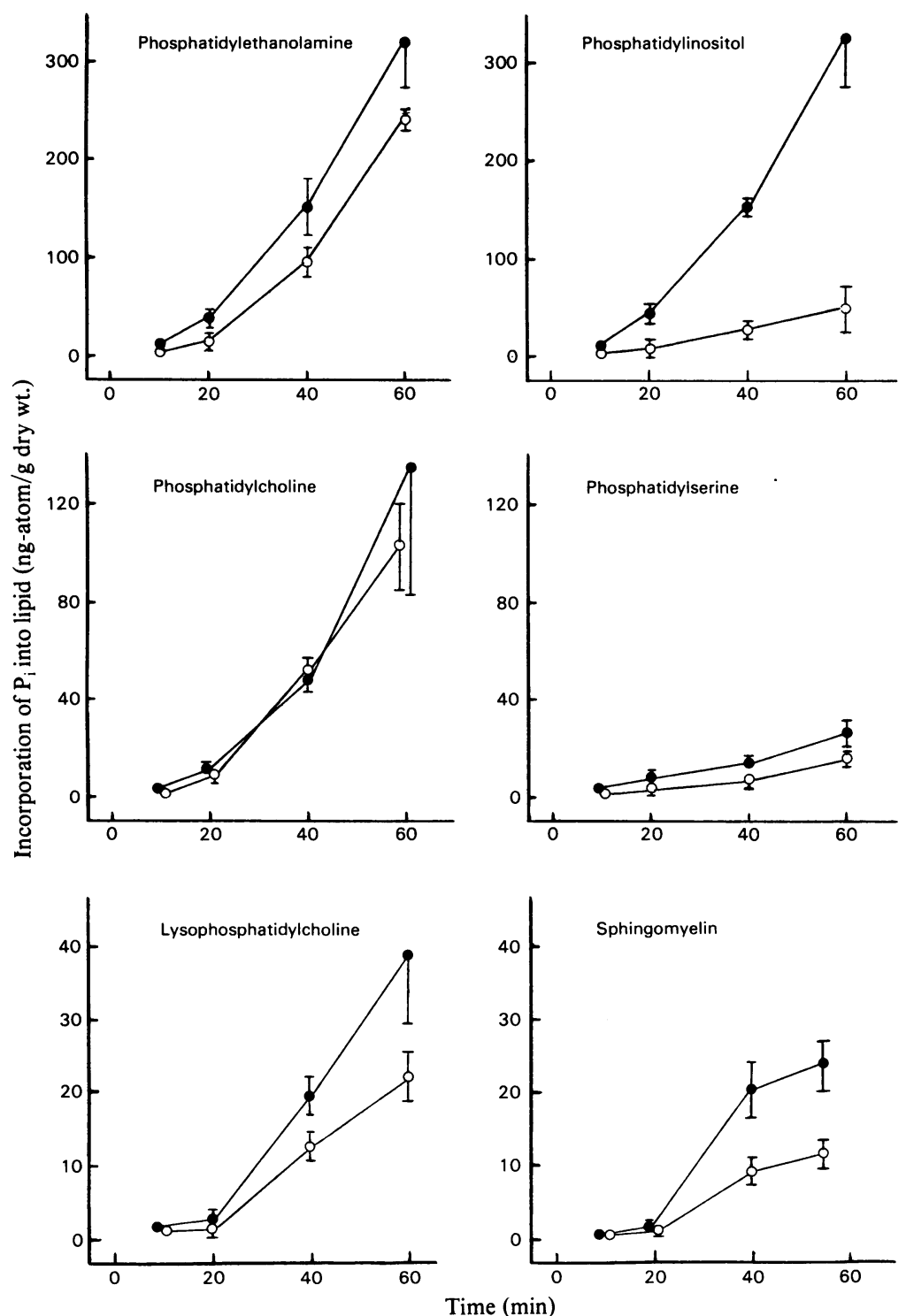

Fig. 1. Time course of $P_{i}$ incorporation into hepatic phospholipids

Hepatocytes were prepared and incubated, with $(0)$ or without $(O) 23 \mathrm{nM}$-vasopressin, as described in the text. Where cells were treated with vasopressin, the hormone was added simultaneously with ${ }^{32} \mathbf{P} \mid \mathbf{P}_{i}$. Incubations were terminated at the times indicated with $0.1 \mathrm{vol}$. of $80 \%(\mathrm{w} / \mathrm{v})$ trichloroacetic acid, and lipids were extracted as described in the text. Results are means \pm S.E.M. of the results from three to five separate hepatocyte preparations.

phosphatidylinositol is shown in Fig. 3(a). At saturating concentrations, vasopressin stimulated phosphatidylinositol labelling about 9-fold. The concentration dependence of this phenomenon was not significantly influenced when hepatocytes were incubated in the presence of insulin (100m-units/ $\mathrm{ml})$.
When extracellular $\mathrm{Ca}^{2+}$ was chelated with excess EGTA, both basal and vasopressin-stimulated $P_{1}$ incorporation into phosphatidylinositol were diminished $(P<0.01$ at all concentration). Nevertheless, in these conditions, saturating vasopressin concentrations still increased phosphatidylinositol labelling 5-fold. 
Table 1. Influence of vasopressin on the incorporation of glycerol and fatty acids into hepatic phospholipids Hepatocytes were prepared as described in the text and incubated for $20 \mathrm{~min}$ with radioactive precursors at the concentration indicated. Lipids were extracted and isolated by thin-layer (phosphatidylcholine, phosphatidylethanolamine) or paper (phosphatidylinositol) chromatography. Results are expressed as means \pm S.E.M. from three separate hepatocyte preparations. ${ }^{*} P$ (versus hormone-free controls) $<0.01$.

Incorporation of precursor ( $\mathrm{nmol} / \mathrm{g}$ dry wt. $/ 20 \mathrm{~min})$ into:

$\begin{array}{clccc}\text { [Vasopressin] } & { }^{14} \text { C-labelled } & \begin{array}{c}\text { Phosphatidyl- } \\ \text { pholine }\end{array} & \begin{array}{c}\text { Phosphatidyl- } \\ \text { ethanolamine }\end{array} & \begin{array}{c}\text { Phosphatidyl- } \\ \text { inositol }\end{array} \\ 0 & \text { Glycerol }(2 \mathrm{mM}) & 144 \pm 27 & 174 \pm 40 & 68 \pm 11 \\ 2.3 \times 10^{-8} & \text { Glycerol }(2 \mathrm{mM}) & 116 \pm 16 & 184 \pm 51 & 156 \pm 5^{*} \\ 0 & \text { Oleic acid (1 mM) } & 375 \pm 22 & 567 \pm 187 & 470 \pm 36 \\ 2.3 \times 10^{-8} & \text { Oleic acid (1 mM) } & 401 \pm 55 & 477 \pm 169 & 758 \pm 55^{*}\end{array}$
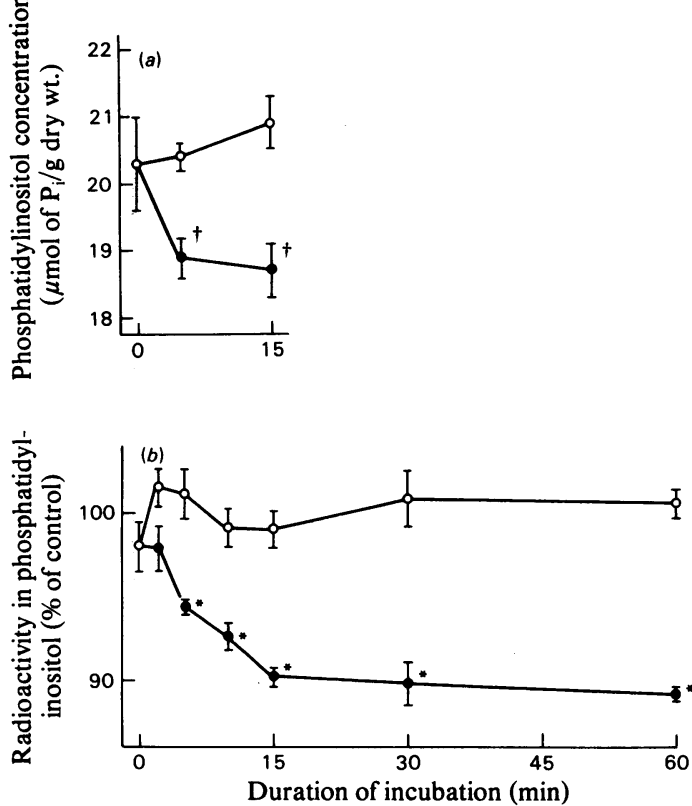

Fig. 2. Time-course of vasopressin-induced phosphatidylinositol breakdown

Hepatocytes were prepared from normal or [2${ }^{3} \mathrm{H}$ ]myo-inositol-injected rats as described in the text and incubated with (O) or without (O) vasopressin $(0.23 \mu \mathrm{M})$ for the periods indicated. $P_{1}$ was assayed in $\mathrm{HClO}_{4}$ digests of separated phosphatidylinositol from non-radioactive hepatocyte suspensions (Fig. $2 a$ ). In hepatocytes prepared from $\left[2-{ }^{3} \mathrm{H}\right]$ inositolpretreated rats, ${ }^{3} \mathrm{H}$ (d.p.m.) in phosphatidylinositol was assayed as described in the text (Fig. 2b). In each experiment using $\left[2-{ }^{3} \mathrm{H}\right]$ myo-inositol-injected rats, phosphatidylinositol content (i.e. radioactivity in phosphatidylinositol) at a given time was calculated as a percentage of the mean phosphatidylinositol content of the controls for all the time periods tested. Results are means \pm S.E.M. for three to five separate hepatocyte preparations. $P$ (versus hormone-free controls): ${ }^{*}<0.01, \dagger<0.02$.
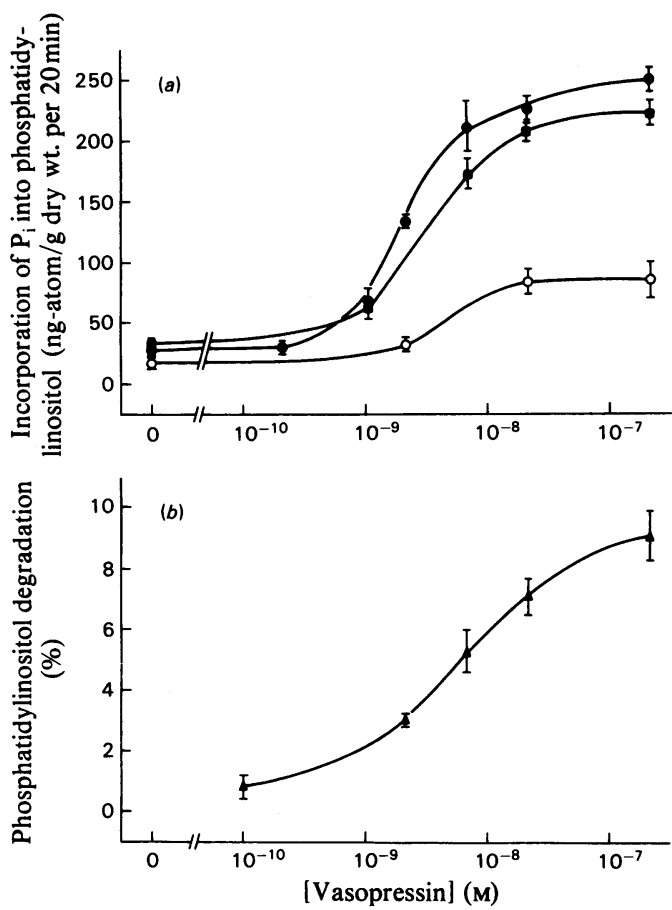

Fig. 3. Concentration dependence of vasopressin-stimulated phosphatidylinositol metabolism: influence of $\mathrm{Ca}^{2+}$ depletion and insulin

Hepatocytes were preincubated for $20 \mathrm{~min}$ in the presence of $\left[{ }^{32} \mathrm{P}\right] \mathbf{P}_{1}$ before hormone additions were made (Fig. $3 a$ ). Incubations were terminated $20 \mathrm{~min}$ later. Cells were incubated in standard medium containing $\mathrm{Ca}^{2+}(2.5 \mathrm{~mm})$ with $(\square)$ or without (O) insulin $(100 \mathrm{~m}$-units $/ \mathrm{ml})$ or in $\mathrm{Ca}^{2+}$-free medium to which 2 mM-EGTA was added at the beginning of the pre-incubation period (O). Hepatocytes prepared from rats injected with $30 \mu \mathrm{Ci}$ of $\left[2{ }^{3} \mathrm{H}\right]$ myo-inositol $20 \mathrm{~h}$ previously were incubated for $15 \mathrm{~min}$ with various concentrations of hormone (Fig. $3 b$ ). Phosphatidylinositol degradation in vasopressin-stimulated hepatocytes is expressed as percentage diminution of lipid-soluble ${ }^{3} \mathrm{H}$ (d.p.m.) compared with hormone-free controls. Results are means \pm S.E.M. for the results from three to seven separate hepatocyte preparations for each point. 
The concentration dependence of vasopressininduced phosphatidylinositol breakdown (Fig. 3b) was very similar to that of the enhanced labelling of the lipid with $\left[{ }^{32} \mathrm{P}\right] \mathbf{P}_{\mathrm{i}}$. Hence the $\mathbf{P}_{1}$-labelling response in hepatocytes seems to be a sensitive and approximately quantitative reflection of vasopressin-stimulated phosphatidylinositol breakdown.

Competitive inhibition of vasopressin-induced phosphatidylinositol labelling by [1-( $\beta$-mercapto- $\beta, \beta-$ cyclopentamethylenepropionic acid),8-arginine]vasopressin

Vasopressin-induced phosphatidylinositol labelling was competitively inhibited by $[1-(\beta$-mercapto$\beta, \beta$-cyclopentamethylenepropionic acid),8-arginine]vasopressin (Fig. 4). The data in Fig. 4 were replotted by the method of Schild (1947) and the $\mathrm{pA}_{2}$ [-log (antagonist concentration that doubles the concentration of agonist required to evoke a half-maximal response)] for this antagonism was found to be 9.0 (Fig. 4, inset).
The subcellular distribution of vasopressin-induced phosphatidylinositol depletion

The distribution of $\left[{ }^{3} \mathrm{H}\right]$ phosphatidylinositol, vasopressin-induced phosphatidylinositol depletion and various subcellular markers amongst primary fractions prepared from vasopressin-treated and control hepatocytes is shown in Table 2. Relative specific activities for these parameters were calculated by the methods of De Duve et al. (1955) and these are presented as distribution diagrams in Fig. 5. Control experiments showed that the $\left[{ }^{3} \mathrm{H}\right]$ phosphatidylinositol content of homogenates did not change if they were maintained on ice during the entire period of the subcellular fractionation.

A substantial separation of the various subcellular components of the hepatocytes was achieved, but it was not possible to determine the distribution of the relatively small phosphatidylinositol depletion provoked by vasopressin treatment for $5 \mathrm{~min}$ with the same precision as the distributions of the other markers in Table 2. Nevertheless it is clear from Table 2 and Fig. 5 that

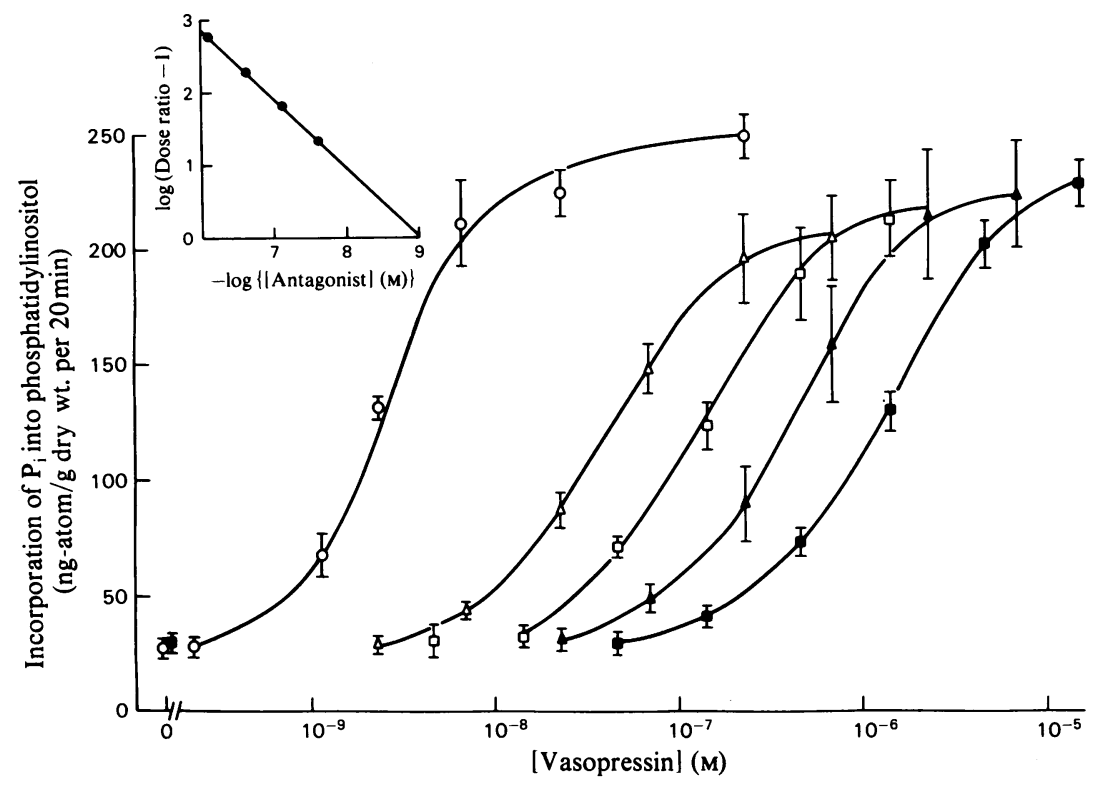

Fig. 4. Inhibition of vasopressin-stimulated phosphatidylinositol labelling by [1-( $\beta$-mercapto- $\beta, \beta$-cyclopentamethylenepropionic acid), Arg $^{8}$ ]vasopressin

Hepatocytes were prepared and incubated in the presence of $\left[\mathrm{Arg}^{8}\right]$ vasopressin as described in Fig. 3(a). The antagonist, [1-( $\beta$-mercapto- $\beta, \beta$-cyclopentamethylenepropionic acid), $\left.\mathrm{Arg}^{8}\right]$ vasopressin was added after 15 min preincubation with $\left.{ }^{32} \mathrm{P}\right] \mathrm{P}_{1}\left(5 \mathrm{~min}\right.$ before the addition of $\left[\mathrm{Arg}^{8}\right]$ vasopressin) to give the following concentrations: $24 \mathrm{nM}(\Delta), 80 \mathrm{nM}(\square), 0.24 \mu \mathrm{M}(\Delta), 0.8 \mu \mathrm{M}(\square)$. Results in the absence of antagonist (O) are taken from Fig. 3(a). Other results are means \pm S.E.M. from three separate hepatocyte preparations. When analysed by the method of Schild (1947), these results yield a $\mathrm{pA}_{2}$ of 9.0 for the inhibition of vasopressin-stimulated phosphatidylinositol labelling by this antagonist (see the inset). 


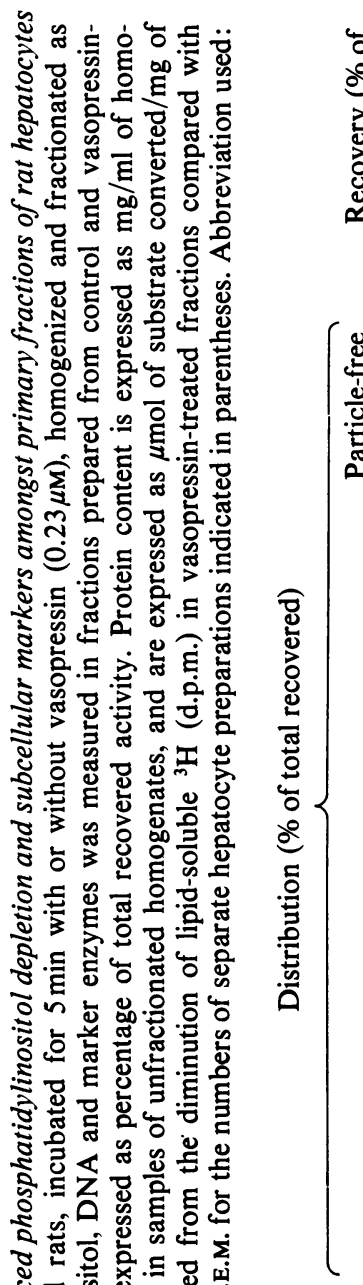

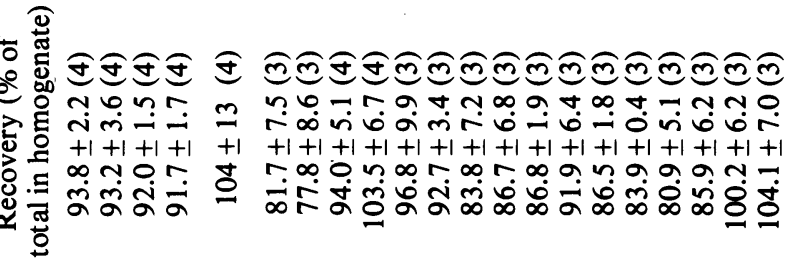

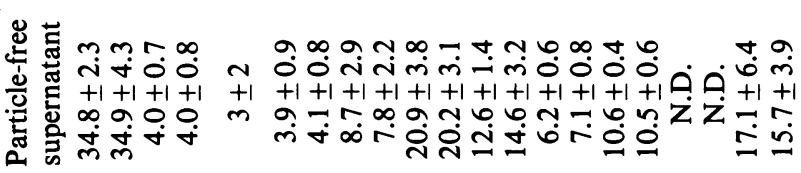

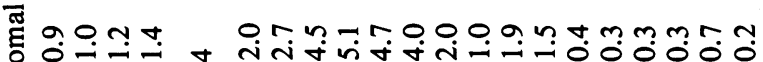

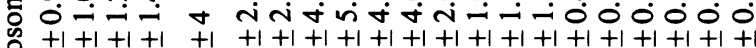

m+l +1 +l $+1+1+1+1+1+1+1+10+1+1+1+1+1$

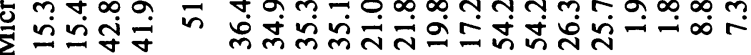

ฮే

$00+1+1+m+1+1+1+1+1+1+1+1+1+1+1+1+1$

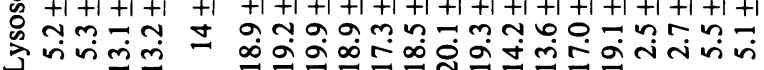

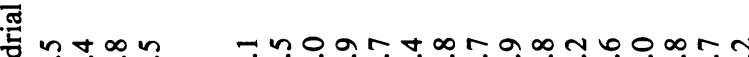

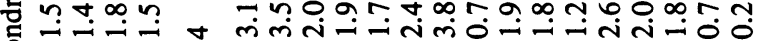
$+1+1+1+1+1+1+1+1+1+1+1+1+1+1+1+1+1+1+1+1+1$ on

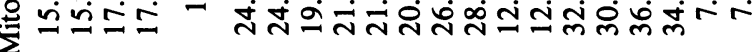

‡ $4+1+1+1+1+1+1+1+1+1+1+1+1+1+1+1+1+1+1+1+1+1$

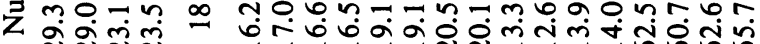

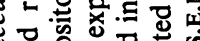
政. \%

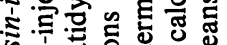
政

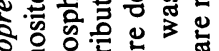

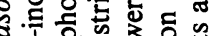
2

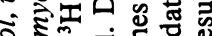

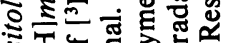

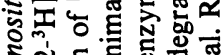
产 范 帘

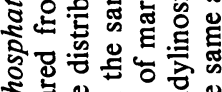

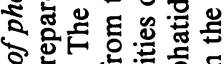

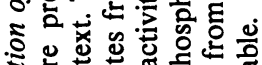

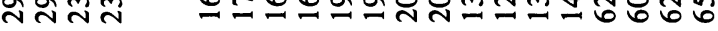

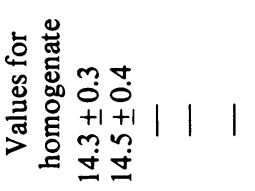

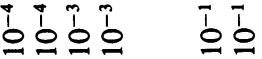
$\times \times \times \times 0$

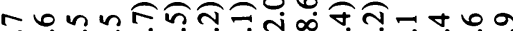

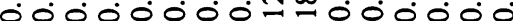
$+1+1+1+1+1+1+1+1+1+1+1+1+1+1+1+1$

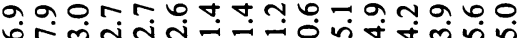

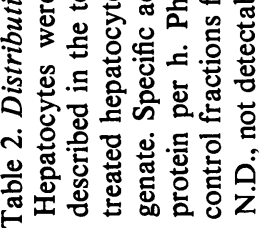

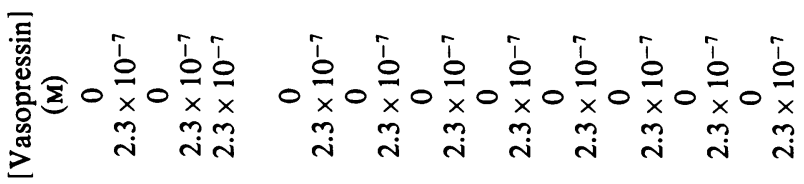

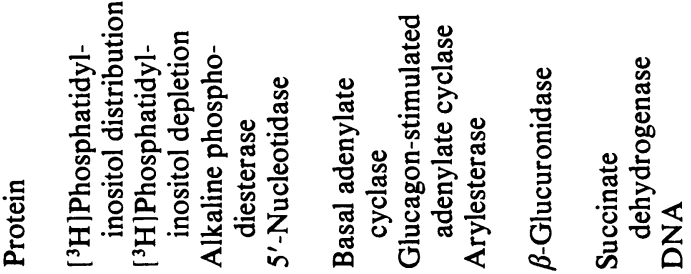




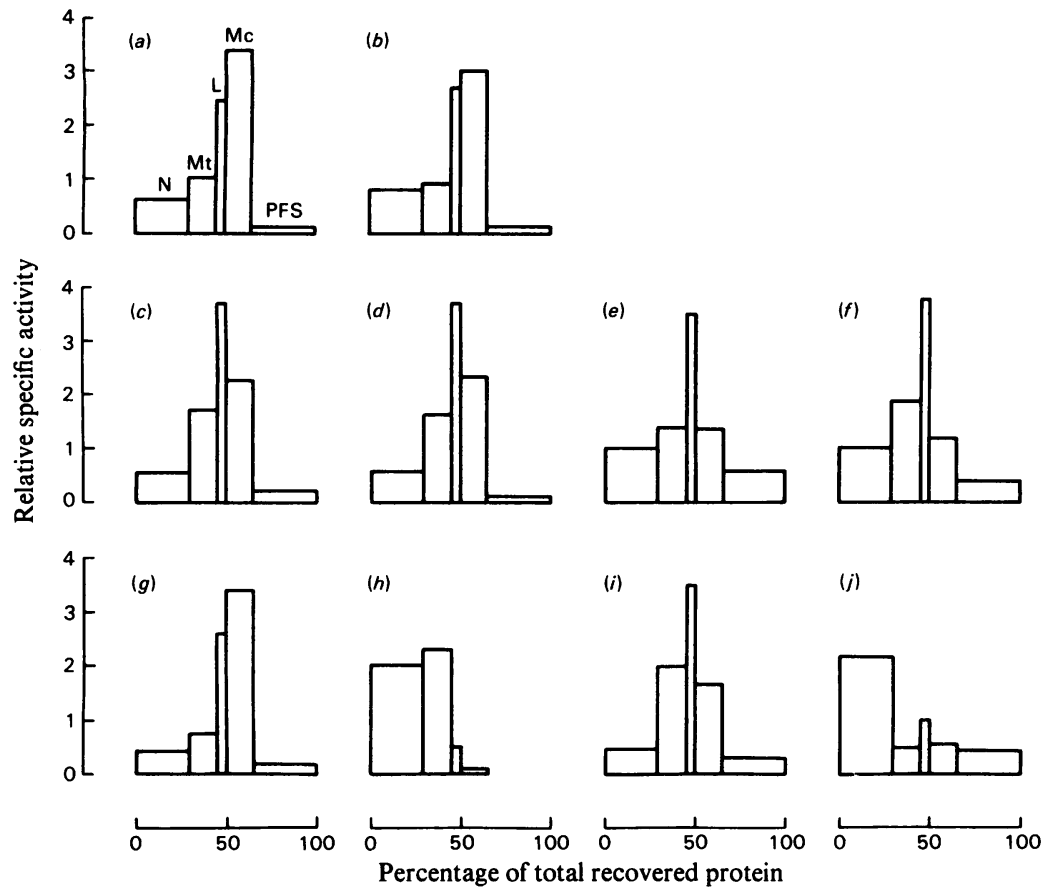

Fig. 5. Distribution of phosphatidylinositol, vasopressin-induced phosphatidylinositol depletion and subcellular markers amongst primary fractions of rat hepatocytes

Hepatocytes were prepared, incubated and fractionated as described in Table 2. The relative specific activities (De Duve et al., 1955) for distributions of phosphatidylinositol, DNA and various marker enzymes are expressed as the means of the values obtained for control and vasopressin-treated cells (from Table 2). Fractions are represented in the order of their isolation, from left to right: nuclear $(\mathrm{N})$, mitochondrial (Mt), lysosomal (L), microsomal (Mc), particle-free supernatant (PFS). Phosphatidylinositol depletion was calculated from the diminution of lipid-soluble ${ }^{3} \mathrm{H}$ (d.p.m.) in vasopressin-treated fractions compared with control fractions from the same animal. The parameters depicted in the Figure are (a) phosphatidylinositol degradation, (b) phosphatidylinositol distribution, (c) 5 -nucleotidase activity, $(d)$ alkaline phosphodiesterase activity, $(e)$ basal adenylate cyclase activity, $(f)$ glucagon-stimulated adenylate cyclase activity, $(g)$ arylesterase activity, $(h)$ succinate dehydrogenase activity, $(i)$ $\beta$-glucuronidase activity and $(j)$ DNA. Results are from three or four separate hepatocyte preparations. Other details are as described in Table 2.

the distribution of phosphatidylinositol depletion in the separated fractions was quite different from all other measured distributions except those of total $\left[{ }^{3} \mathrm{H}\right]$ phosphatidylinositol and the endoplasmicreticulum marker arylesterase. At the precision with which our measurements were made, the distribution of phosphatidylinositol depletion did not differ significantly from either of these parameters.

\section{Discussion}

Of the major phospholipids, only phosphatidylinositol exhibits significantly enhanced $P_{i}$ incorporation after vasopressin treatment in hepatocytes (see also Kirk et al., 1977). Hence the effect of vasopressin is specific to phosphatidylinositol metabolism and not a more general metabolic effect such as on the labelling of intracellular ATP. As in other tissues (for references, see Jones et al., 1979), enhanced phosphatidylinositol labelling in hepatocytes is accompanied by a rapid diminution in the cellular concentration of the lipid. Thus the primary effect of vasopressin is to promote degradation of hepatic phosphatidylinositol rather than its synthesis de novo (see also Billah \& Michell, 1979).

Unlike some other ligands, which promote only the incorporation of $\left[{ }^{32} \mathrm{P}\right] \mathrm{P}_{i}$ into phosphatidylinositol in their target tissues (for review, see Michell, 1975), vasopressin also enhances phosphatidylinositol labelling with $\left[\mathrm{U}-{ }^{14} \mathrm{C}\right]$ glycerol and $\left[1-{ }^{14} \mathrm{C}\right]$ oleic acid, but to a lesser extent (2-fold) than is observed with $\left[{ }^{32} \mathrm{P}\right] \mathrm{P}_{\mathbf{i}}$ (9-fold). The ineffectiveness of other stimuli in enhancing glycerol or fatty-acid incorporation into phosphatidylinositol has been cited as 
evidence for a closed cycle of phosphatidylinositol breakdown and re-synthesis via diacylglycerol and phosphatidic acid (for review, see Michell, 1975). However, there have now been reports of ligandstimulated glycerol and fatty-acid incorporation into phosphatidylinositol in an appreciable number of tissues (see Table II of Michell, 1975; Shohet, 1970; Calderon et al., 1979). Such reports are not inconsistent with the cycle of degradation and resynthesis referred to above if newly synthesized phosphatidate is able to enter the same pool as is generated from the diacylglycerol liberated during phosphatidylinositol degradation. The liver is an organ that supports a high rate of phosphatidate synthesis de novo, and the present results suggest that vasopressin provokes a small increase in the proportion of this newly synthesized phosphatidate that is converted into phosphatidylinositol.

A common feature of receptors that mediate enhanced phosphatidylinositol metabolism in a variety of tissues is their ability to provoke other physiological responses by increasing cytosolic $\mathrm{Ca}^{2+}$ concentration (Michell, 1979). Indeed, such responses are frequently dependent on the presence of extracellular $\mathrm{Ca}^{2+}$. In the present study, $\mathrm{Ca}^{2+}$ depletion decreased basal or hormone-stimulated $P_{1}$ incorporation into phosphatidylinositol. Nevertheless, under conditions of $\mathrm{Ca}^{2+}$ chelation that completely suppress the hormone's activation of glycogen phosphorylase (Whitton et al., 1977; Blackmore et al., 1978), vasopressin still enhanced phosphatidylinositol labelling over the same concentration range as was effective in the presence of $2.5 \mathrm{mM}-\mathrm{Ca}^{2+}$. This observation is in agreement with the findings of Billah \& Michell (1979), who also observed that ionophore A23187, which elevates cytosolic $\mathrm{Ca}^{2+}$ concentration and activates glycogen phosphorylase in hepatocytes (Blackmore et al., 1978), did not influence basal or vasopressin-stimulated phosphatidylinositol breakdown (the hormone-stimulated event) or the subsequent labelling response. Taken together, these results indicate that vasopressin-stimulated phosphatidylinositol breakdown in hepatocytes, like that provoked by ligands in several other tissues (see Billah \& Michell, 1979 , for references), is not a consequence of $\mathrm{Ca}^{2+}$ mobilization in the cytosol. It should be noted here that recent work has revealed a subgroup of cell types, mainly derived from stem-cells in the bonemarrow (platelets, polymorphonuclear leucocytes and mast cells), in which phosphatidylinositol breakdown is, at least in part, a response to a rise in cytosol $\mathrm{Ca}^{2+}$ concentration (Lapetina \& Cuatrecasas, 1979; Bell \& Majerus, 1980; Cockcroft et al., 1980); the significance of this is not yet clear.

The concentration of vasopressin required to provoke half-maximal phosphatidylinositol breakdown (4.8 nM; Fig. 3) is approx. 16-fold greater than that required to cause half-maximal activation of glycogen phosphorylase in hepatocytes $(0.3 \mathrm{nM}$; Kirk et al., 1979). Current techniques do not allow us to detect significant phosphatidylinositol depletion at this latter concentration of vasopressin. However, studies in two laboratories suggest that the concentration of vasopressin that provokes halfmaximal phosphatidylinositol breakdown is very similar to the $K_{\mathrm{a}}$ for vasopressin binding to hepatic receptors (Cantau et al., 1980; Knowles, 1981). These data suggest that only a small proportion of hepatic vasopressin receptors need be occupied to activate glycogen phosphorylase, but that the degree of activation of phosphatidylinositol breakdown is approximately proportional to the extent of receptor occupation by the agonist. These observations are consistent with the suggestion that phosphatidylinositol degradation is a direct consequence of vasopressin-receptor interaction, which might evoke the mobilization of $\mathrm{Ca}^{2+}$ in the cytosol that is responsible for physiological effects such as glycogenolysis (Kirk et al., 1977, 1979, 1980; Michell et al., 1979; Billah \& Michell, 1979).

Insulin is capable of diminishing the extent of vasopressin-induced glucose release from the perfused rat liver (Kirk \& Hems, 1979). However, the present results indicate that insulin does not influence vasopressin-induced phosphatidylinositol turnover (Fig. 3). If the stimulation of phosphatidylinositol turnover is intrinsic to the mechanism whereby vasopressin mobilizes intracellular $\mathrm{Ca}^{2+}$ and activates glycogen phosphorylase in liver, then the suppression by insulin of hepatic glucose release, but not of phosphatidylinositol turnover, may indicate that insulin acts directly on the enzymes of glycogen metabolism rather than by inhibition of stimulus-response coupling at the vasopressin receptor.

We and others have previously reported that the ligand selectivity of the hepatic vasopressin receptor is very similar to that of the receptors responsible for mediating the pressor response to the hormone in vivo (Kirk et al., 1978; Keppens \& De Wulf, $1979)$. The present observation that $[1-(\beta$-mercapto$\beta, \beta$-cyclopentamethylenepropionic acid),8-arginine] vasopressin antagonizes vasopressin-stimulated phosphatidylinositol labelling with a $\mathrm{pA}_{2}$ of 9.0 provides further evidence of the similarity between hepatic and pressor receptors for vasopressin, since this analogue antagonizes the pressor response to vasopressin in vivo with a $\mathrm{pA}_{2}$ of 8.35 (Kruszynski et al., 1980). Recent experiments have also indicated that this antagonist inhibits vasopressin-stimulated phosphatidylinositol labelling in vascular smooth muscle with a $\mathrm{pA}_{2}$ of 8.1 (Takhar \& Kirk, 1981), and the similarity between the apparent affinities of the antagonist in these three assay systems supports our previous suggestion that a 
single class of vasopressin receptors ( $\mathrm{V}_{1}$-receptors) is responsible for both the hepatic and pressor actions of vasopressin (Kirk et al., 1979; Michell et al., 1979).

The suggestion that vasopressin-stimulated phosphatidylinositol degradation is involved in the coupling of receptor occupation to the mobilization of $\mathrm{Ca}^{2+}$ in the cytosol (Kirk et al., 1979, 1980) leads to the prediction that phosphatidylinositol breakdown should be localized at the plasma membrane. The present results do not allow a conclusion on this point, in that a constant proportion of the initial phosphatidylinositol complement was lost from all of the subcellular fractions derived from cells stimulated with vasopressin for $5 \mathrm{~min}$. The relatively close resemblance between the subcellular distributions of phosphatidylinositol depletion, of the total phosphatidylinositol of the cell, and of arylesterase, and enzyme localized in the endoplasmic reticulum, presumably reflect the fact that the endoplasmic reticulum contains the majority of the cellular presumably reflects the fact that the endoplasmic explanation of these observations would be that phosphatidylinositol breakdown occurs only at the endoplasmic reticulum, in which case an intracellular messenger other than $\mathrm{Ca}^{2+}$ would have to carry the vasopressin message from the plasma membrane to endoplasmic reticulum. A second alternative, that vasopressin might induce rapid phosphatidylinositol breakdown at all membranes throughout the cell, would also invoke some unknown intracellular messenger. The latter alternative also seems unlikely because individual enzyme-catalysed reactions do not usually occur at all intracellular sites at precisely equal rates. Thirdly, and maybe most likely, it is possible that phosphatidylinositol breakdown initially occurs at some single cellular locus and that the phosphatidylinositol exchange proteins of the cytosol (Zborowski \& Wojtczak, 1975; Zborowski, 1979) then rapidly re-equilibrate the remaining phosphatidylinositol amongst all cellular compartments. If this ultimately proves to be the case, then the information reported here will constitute a convincing demonstration of the rapidity with which such phospholipid exchange occurs within the intact cell. It would also mean that the identification of the cellular site at which phosphatidylinositol breakdown occurs might not be amenable to study by subcellular fractionation techniques such as those described above.

We thank the M.R.C. for financial support. During some of the work reported here C. J. K. was in receipt of a Beit Memorial Fellowship for Medical Research.

\section{References}

Assimacopoulos-Jeannet, F. D., Blackmore, P. F. \& Exton, J. H. (1977) J. Biol. Chem. 252, 2662-2667

Baginski, E. S., Zak, B. \& Foa, P. P. (1967) Clin. Chem. $13,326-332$

Bell, R. L. \& Majerus, P. W. (1980) J. Biol. Chem. 255, 1790-1792

Billah, M. M. \& Michell, R. H. (1978) Biochem. Soc. Trans. 6, 1033-1035

Billah, M. M. \& Michell, R. H. (1979) Biochem. J. 182, 661-668

Blackmore, P. F., Brumley, F. T., Marks, J. L. \& Exton, J. H. (1978) J. Biol. Chem. 253, 4851-4858

Calderon, P., Furnelle, J. \& Christophe, J. (1979) Biochim. Biophys. Acta 574, 404-413

Cantau, B., Keppens, S., De Wulf, H. \& Jard, S. (1980) J. Receptors Res. in the press

Chen, J.-L. J., Babcock, D. F. \& Lardy, H. A. (1978) Proc. Natl. Acad. Sci. U.S.A. 75, 2234-2238

Cockcroft, S., Bennett, J. P. \& Gomperts, B. D. (1980) FEBS Lett. 110, 115-118

De Duve, C., Pressman, B. C., Gianetto, R., Wattiaux, R. \& Appelmans, F. (1955) Biochem. J. 60, 604-617

Garrison, J. C., Borland, M. K., Florio, V. A. \& Twible, D. A. (1979) J. Biol. Chem. 254, 7147-7156

Getz, G. S., Bartley, W., Stirpe, F., Notton, B. \& Renshaw, A. (1962) Biochem. J. 83, 181-191

Getz, G. S., Bartley, W., Lurie, D. \& Notton, B. (1968) Biochim. Biophys. Acta 152, 325-339

Groener, J. E. M. \& Van Golde, L. M. G. (1977) Biochim. Biophys. Acta 487, 105-114

Hems, D. A. \& Whitton, P. D. (1973) Biochem. J. 136, 705-709

Hems, D. A., Rodrigues, L. M. \& Whitton, P. D. (1978a) Biochem. J. 172, 311-317

Hems, D. A., Davies, C. J. \& Siddle, K. (1978b) FEBS Lett. 87, 196-198

Houslay, M. D., Metcalfe, J. C., Warren, G. B., Hesketh, T. R. \& Smith, G. A. (1976) Biochim. Biophys. Acta 436, 489-494

Jones, L. M. \& Michell, R. H. (1974) Biochem. J. 142, 583-590

Jones, L. M., Cockcroft, S. \& Michell, R. H. (1979) Biochem. J. 182, 669-676

Keppens, S. \& De Wulf, H. (1979) Biochim. Biophys. Acta 588, 63-69

Keppens, S., Vandenheede, J. R. \& De Wulf, H. (1977) Biochim. Biophys. Acta 496, 448-457

Kirk, C. J. \& Hems, D. A. (1974) FEBS Lett. 47, $128-131$

Kirk, C. J. \& Hems, D. A. (1979) Biochim. Biophys. Acta $583,474-482$

Kirk, C. J., Verrinder, T. R. \& Hems, D. A. (1977) FEBS Lett. 83, 267-271

Kirk, C. J., Verrinder, T. R. \& Hems, D. A. (1978) Biochem. Soc. Trans. 6, 1031-1033

Kirk, C. J., Rodrigues, L. M. \& Hems, D. A. (1979) Biochem. J. 178, 493-496

Kirk, C. J., Billah, M. M., Jones, L. M. \& Michell, R. H. (1980) Horm. Cell Regul. 4, 73-88

Knowles, R. G. (1981) Biochem. Soc. Trans. in the press

Krebs, H. A. \& Henseleit, K. (1932) Hoppe-Seyler's Z. Physiol. Chem. 210, 33-36 
Kruszynski, M., Lammek, B., Manning, M., Seto, J., Haldar, J. \& Sawyer, W. H. (1980) J. Med. Chem. 23, 364-368

Lapetina, E. G. \& Cuatrecasas, P. (1979) Biochim. Biophys. Acta 573, 394-402

Lapetina, E. G. \& Michell, R. H. (1972) Biochem. J. 126, 1141-1147

Lloyd-Davies, K. A., Michell, R. H. \& Coleman, R. (1972) Biochem. J. 127, 357-368

Ma, G. Y. \& Hems, D. A. (1975) Biochem. J. 152 , 389-392

Michell, R. H. (1975) Biochim. Biophys. Acta 415, 81-147

Michell, R. H. (1979) Trends Biochem. Sci. 4, 128-131

Michell, R. H. \& Hawthorne, J. N. (1965) Biochem. Biophys. Res. Commun. 21, 333-338

Michell, R. H., Jafferji, S. S. \& Jones, L. M. (1976) FEBS Lett. 69, 1-5

Michell, R. H., Kirk, C.J. \& Billah, M. M. (1979) Biochem. Soc. Trans. 7, 861-865
Ontko, J. A. (1972) J. Biol. Chem. 247, 1788-1800

Schild, H. O. (1947) Br. J. Pharmacol. 11, 189-206

Seglen, P. O. (1976) Methods Cell Biol. 13, 29-83

Shephard, E. H. \& Hübscher, G. (1969) Biochem. J. 113, 429-440

Shohet, S. B. (1970) J. Lab. Clin. Med. 75, 659-672

Stubbs, M., Kirk, C. J. \& Hems, D. A. (1976) FEBS Lett. 69, 199-202

Takhar, A. P. S. \& Kirk, C. J. (1981) Biochem. J. 194, 167-172

Tolbert, M. E. M., White, A. C., Aspry, K., Cutts, J. \& Fain, J. N. (1980) J. Biol. Chem. 255, 1938-1944

Whitton, P. D., Rodrigues, L. M. \& Hems, D. A. (1977) Biochem. Soc. Trans. 5, 992-994

Williamson, D. H., Ilic, V., Tordoff, A. F. C. \& Ellington, E. V. (1980) Biochem. J. 186, 621-624

Zborowski, J. (1979) FEBS Lett. 107, 30-32

Zborowski, J. \& Wojtczak, L. (1975) FEBS Lett. 51, 317-320 